\title{
THE USE OF OPEN AND DISTANCE LEARNING FOR CORRECTIONAL EDUCATION: THE VIEWS OF PRISON INMATES OF NSAWAM MEDIUM SECURITY PRISON (NMSP), GHANA.
}

\author{
Francis Owusu-Mensah \\ Institute for Distance and e-Learning, University of Education, Winneba, Ghana. \\ francisowusumensah@gmail.com / fomensah@uew.edu.gh
}

\begin{abstract}
This study explored the views of the Inmates of Nsawam Medium Security Prison (NMSP) in Ghana about using Open and Distance learning building their human resource while serving their jail terms. The study employed qualitative research methodology which made use of semi-structured interviews to collect qualitative data. Fifteen final year students of two formal education programmes in the prison were purposively selected to participate in the study. The study found among others that prisoners in NMSP possess adequate knowledge and understanding of potential benefits of $O D L$ in equipping them with knowledge and skills they will need to live a meaningful life after prison. The inmates were also able to identify the financial and logistical support they will need to embark on a successful ODL programme. The author recommended that government should provide financial support and logistical support for effective correctional educational through $O D L$.
\end{abstract}

KEYWORDS: open and distance learning, correctional education, meduim security prison

\section{INTRODUCTION}

The security of a nation is paramount to its existence. A state of pandemonium, fear and anxiety are the last things any sane person in a country would wish for. This is because for people to engage in economic activities that will enable them earn a living and engage in other socio-economic activities, an atmosphere of peace and tranquility are pre-requisite (Hagan, 2013). People who commit crime constitute one of the sources of threats to the peace and tranquility of any nation. Governments of all nations have tried to maintain law and order through security institutions like the Armed Forces, the Police, the Prisons or Correctional Institutions, among others. Correctional institutions have a peculiar way of contributing their quota to the preservation and promotion of internal peace of a nation (Hagan, 2013).

In Ghana, according to National Redemption Council (NRC) Decree 46 (1) 'it shall be the duty of the Prison Service to ensure the safe custody and welfare of prisoners and whenever practicable to undertake reformation and rehabilitation of prisoners' (Ampratwum, 2002, p.9). This implies that, the Service is mandated to provide internal security by ensuring safe custody and welfare of prisoners before it attends to issues of reformation and rehabilitation. To fulfill this mandate, the 1992 Constitution of the Republic of Ghana, Article 205, (1) empowers the government to equip and maintain the Ghana Prisons Service to perform its traditional role effectively and efficiently. Therefore, inmates who are expected to have access to correctional interventions such as formal education, non-formal education, vocational or technical training and craftsmanship to equip them with employable skills may not be able to do so. In most cases, priority may be given to safe custody and welfare 
of prisoners, before the rest of resources are extended to reformation and rehabilitation of prisoners (Antwi, 2015). Like in Canadian societies where rehabilitation is observed as the central goal of federal prisoners (Griffiths cited in Antwi, 2015), offenders are entitled to professional counselling to mitigate specific risk factors such as substance abuse, anger, violence, sexual offences to reduce the criminogenic needs, ensure attitudinal transformation and the motivation of offenders to succeed in their social milieu.

The realizations of these objective(s) and others have been obstructed by certain factors. For example, Ayodele (1993) reported that the rate at which ex-convicts are returning to prison is alarming. Prisons have in modern times become training ground and school for a new category of criminals and patterns of crime unknown to the society (Ayodele, 1993). In addition, Civil Liberty Organization (1993) reported that the prison is just where one learns one or two mistakes that led to one being arrested so that inmates get smarter by sharing experience with more learned colleagues. In line with these conditions, Adelaja (2009) also noted that prisoners left unoccupied with constructive and positive activities are likely to perfect their criminal activities through the learning of new tricks from other inmates. Therefore, public safety is not guaranteed when prisoners are released into homelessness, with no prospect of employment. The prison conditions in Nigeria are not different from Ghana.

In reality, criminality becomes more alarming when crime committed by prisoners elicits fear and anger and breeds mutual distrust and turns communities into fortresses (AhwaYankey, 2014). This is further compounded when crime erodes public confidence in state institutions like prisons with its effects on costs to prison management. Counselling psychologists like Notshulwana (2012) viewed that, correctional education, particularly distance education is one of the key channels that could be used to reform or change prisoners from committing crime in our communities and/or organizations.

\section{Statement of the Problem}

Petersilia (2003) noted that, it is societal and political influence that greatly hinders distance education as a rehabilitative tool for inmates who have the interest, ability and zeal to learn in prison custody. However, some policy makers call for less funding for rehabilitative programmes. For it encourages increased spending for more prisons and longer sentences (Petersilia, 2003).In Ghana, some correctional officers and/or students who pursue penology, criminology, social work, sociology, counselling, psychology, law and others in tertiary institutions usually seek permission from prison administration to collect data for their project works or theses. In view of this academic opportunity, there has been few studies about prisoners' reformation, rehabilitation and re-integration in Ghana (Acheampong, 2007; Rabbles, 2011; Mfum, 2012; Hagan, 2013; Boamah, 2014; Antwi, 2015).

For example, Antwi's (2015) work focused on social re-integration of offenders and recidivism in Ghana whilst Boamah's (2014) work revealed that, the interplay of structural background factors and informal social control mechanisms predict the early onset of crime in Ghana due to socio-cultural and economic reasons. Mfum's work (2012) on the prospects and challenges of prison libraries in Ghana discovered that literate prisoners of all categories desire library and information services for academic, recreational and 
rehabilitative purposes. This facility helps prisoners in the rehabilitation programmes. Hagan's (2013) study informed his readers that vocational and educational programmes were the main rehabilitation programmes in the Nsawam Medium Security Prisons.

Research works by (Acheampong, 2007; Rabbles, 2011; Mfum, 2012; Hagan, 2013; Boamah, 2014; Antwi, 2015) did not however emphasize on prisoners' view and experiences of distance education and its influence on behavioural change towards crime in Ghana, particularly, at the Nsawam Medium Security Prisons where these researchers did their study. It is this gap, which prompted the researcher to look into the matter. In a question form, the issue under investigation is: What are the prisoners' view of distance education as a mode of acquiring knowledge and skills whilst in incarceration?

\section{Purpose of the Study}

The key concern of the study was to examine prisoners' views and experiences of distance education as a means correctional education.

\section{Objective of the Study}

Specifically, the study sought to ascertain the prisoners' awareness on distance education for acquisition of certificates at Nsawam Medium Security Prison.

\section{Research Question}

The study was guided by the research question below:

What is the prisoners' awareness on distance education for acquisition of certificates at Nsawam Medium Security Prison?

\section{Significance of the Study}

The study could assist the Ghana Prisons Service in addressing some of the identified challenges of correctional education. Therefore, this study could help in the rehabilitation of offenders by improving literacy levels of most incarcerated prisoners at the Nsawam Medium Security Prison in preparation for reintegration into communities.

\section{LITERATURE UPTAKE}

\section{The Concept of Lifelong learning and Open and Distance Learning}

The term lifelong learning describes the need for people to continue their education and training throughout life because they will face multiple careers in changing economies and enjoy longer lives in evolving societies (Daniel, 2005). Thus, lifelong learning implies learning through one's life irrespective of geographical location.

By making learning possible anytime and anywhere, open and distance learning (ODL) is a powerful tool for supporting lifelong learning. 'Technology-based based teaching is creating new educational systems that eliminate boundaries of geography, jurisdiction and 
time whilst integrating academic and real world concerns and giving students more extensive and affordable choices' (COL, 2005).

Open and Distance Learning (ODL) has grown into an important strategy in resolving problems of access to education (UNESCO, 2004).Open learning is a term with no universally agreed definition. To some 'open' will indicate open entry and access to learning opportunities, and the focus will be on the removal of barriers to learning opportunities. To others it may include aspects of methods and organization, with the consequence that 'open learning' may sometimes be substituted by flexible learning. ODL in most cases shares the concern for openness and flexibility. Holmberg (1990) described ODL as an educational process in which a significant proportion of the teaching is conducted by someone removed in space and/or time from the learner. ODL may involve the use of a range of media, such as print, written correspondence, audio, video and computer based media and networks as well as multimedia, both for presentation of information and for communication between participants.

\section{Some Benefits of ODL to Reformation of Prison}

The use of ODL has made possible to communicate with very large numbers of people through a single act of writing or broadcasting, very many people than a teacher or lecturer could teach in a face-to-face lesson. This has become possible mainly through the use of information and communications Technology (ICT) (Saint 1999). The factors which have made ODL play a potential role in prison reformation the following:

- The increasing demand for reformation of persons for higher education especially the inmates who missed the opportunity at their youthful stages to gain admission to conventional universities.

- The need to exploit the vast potential of modern technology for education purposes of transference of knowledge, experience of inmates and to reduce recidivism.

- The need to update the knowledge of inmates through lifelong learning because of the exponential developments in information gathering and storage as well as rapidly dynamic analysis and application, which tend to render previously acquired knowledge obsolete very fast.

- In order to relate the education of the inmates to work (Chukwunka, 2017).

Recognizing the important role ODL can play in correctional education, The National Open University of Nigeria (NOUN) has mounted postgraduate and undergraduate programmes for prisoners in Nigeria (NOUN, 2018) As at 2018, there were 465 undergraduate students, 23 Master's degree and two PhD students (NOUN, 2018).

In a study on a study on NOUN and reformation of prison inmates through ODL, Chukwunka, (2017), found a significant relationship between the acceptability of NOUN and the acceptability and the acceptability of NOUN as an important factor in developing learning potentials for reformation of the inmates of Ikoyi prisons, Lagos. The findings from this Nigeria study corroborate the view that knowledge and skill acquisition is necessary for prison reformation Ugwuoke (2015). The present study focuses on the views prison inmates in Ghana on the use of ODL for correctional education. 


\section{Research Approach}

The researcher adopted the qualitative method for the study of views of the prisoners of Nsawam Medium Security Prisons (Ghana) about distance education and its role in correctional education in Ghana. Qualitative research is concerned with studying social systems, such as a school within a prison to understand how that social system works and how it shapes the prisoners within it. Secondly, the qualitative method captures educational reality as participants experience it (Check \& Schutt, 2012).

The most appropriate data collection strategy for a phenomenological research is the profound interview. Existing literature (Kyale \& Brinkman, 2009: Marshall \& Rossman, 2010) coincides. In that, the phenomenological interview should be open or semistructured. The interview allowed the researcher to address the phenomenon profoundly, by providing a space of aperture for the participants to express their experiences in detail, approaching reality as faithfully as possible. The detailed descriptions or interpretations brought by the participants in the profound-phenomenological interview should be a representative of experienced reality as possible. It was therefore vital for me as a researcher to have good skills and /or competency in interviewing when the phenomenological design was adopted for the study.

\section{Population}

The target population for the study was all students pursuing senior high school and ICT programmes and those who have completed the programmes at Nsawam Medium Security Prison. The accessible population for the study was 40 final year students of Senior High School and Information Technology and Communication Students (ICT) programmes. The final year students were chosen for the study because they were in the terminal year of their academic programmes. Therefore, the problem of career selection and the possibility of being able to continue with their studies were likely to be more salient for them than the rest of the students in the lower forms/classes.

Nsawam Medium Security Prison was chosen for the study because, formal education in Ghanaian prisons started at NMSP. The station also serves as the second largest prison in Ghana established in 1960 with a prison in Ghana

In terms of education background of inmates, about one-third had completed Primary and Junior High School (Revised Prison Form 20, Second Quarter Report for 2017).This empirical data reveals that, the majority of the youth who are in their productive stage at the Nsawam Medium Security Prison may very much have the potential, zeal and interest in pursuing academic laurels for life.

\section{Sample and Sampling Technique}

For this study, the researcher used 15 inmate students as sample because of the need to probe the views and experiences of participants on distance education for correctional education more deeply than a representative sample would allow for. Also, the researcher believed that by using an exploratory sample, sufficient data would be collected to answer the research question and achieve the objective of the study (Denscombe, 2010) 
In line with Patton's (2003), explanation on purposive sampling as the selection of cases with information that will enhance the questions being studied, the researcher adopted purposive sampling technique in selecting 15 inmate-students (i.e. Seven SHS students and Eight ICT students) from the final year group These participants were given pseudonyms names P1.........P15. The focus of the data collection was on prisoners' views and experiences and its influence on behavioural change towards crime in Ghana.

The sampled 15 participants were interviewed at different periods. Henniink et al., (2012) explained that due to the in-depth nature of qualitative research, few study participants were needed, as the purpose was to achieve in-depth information (rather than breath) by 'mining' each participant deeply for their experiences on the research topic.

\section{Research Instruments}

The main instrument used in collecting data for this study was a researcher-constructed interview guide tagged "Inmate-Students Interview Guide" (ISIG) for interviewing participants. The interview guide was developed based on the key issues in the research question that guided the study (Agordzo, Akplu \& Forde, 2013).

\section{Issue of 'authenticity' and 'trustworthiness' in the study.}

Several steps were taken in the study to address 'the authenticity' and 'truthfulness' in the study. The researcher used reflexive journaling to log his feelings during the research process. Journal entries were reviewed, both positive and negative feelings. In this study, two Research Assistants were used: one was used for coding, and the other for discussing thoughts as the researcher progressed through the research process.

\section{Data Collection Procedure and Analysis}

Permission was sought from the Officer In-Charge of NMS to enter the prison to interact with the inmates. After following the long and rigorous procedures, access was finally granted for my two Research Assistant and I to enter the prison to interview the inmates.

Data was analyzed qualitatively by reading through the transcript iteratively and identifying the emerging theme. Verbatim quotations were used to support the claim that came out of the views.

\section{FINDINGS}

\section{Knowledge about Distance Education}

The purpose of this sub-theme was to elicit participants' knowledge and level of awareness about distance education in Ghana. The responses indicated that participants were well aware about distance education opportunities in Ghana. However, while some of the participants knew about distance education before coming to the prison, other inmates got to know about it while they were in the prison. For example, one participant noted:

I knew about distance education before I came to prison, provision of distance education makes it highly suitable to older learners in employment as well as younger learners unwilling to sacrifice the 
prospects of working and schooling especially where the costs of schooling is high. P1).

This response was corroborated by almost all the participants. For example a highly educated inmate added:

distance education can effectively reach those learners who have been denied access to higher education as a result of circumstances. For example, people who dropped out of school or were imprisoned whilst pursuing educational programmes in school the second chance to education. (P2).

Another participant ( P5) had this to say;

We were informed in the prison block that Wisconsin University was going to extend distance education programme to the Medium Security Prison

The responses from the inmates point out clearly that they are well-informed concept and benefits of ODL. Again, the media through which participants got to know about distance education varied among participants. The commonly cited sources included Internet (www.myjoyonline.com), Friends, Radio adverts, Television adverts, Announcement in the prison block, classroom, school assembly.

\section{Institutions that Offer Distance Education}

It was realized that majority of the participants were familiar with some of the institutions that offered distance education opportunities in Ghana. Examples of public institutions mentioned by the participants were:

1. University of Cape Coast (UCC)

2. University of Ghana (UG)

3. Kwame Nkrumah University of Science and Technology (KNUST)

4. University of Education, Winneba (UEW)

Other private universities were also mentioned. They included:

1. Regional Maritime University College

2. Wisconsin University College

\section{Preferred Programme of Study}

With respect to the preferred programme of study when given the opportunity to do distance education was offered, participants were quick to highlight a host of programmes. Majority of these programmes were related to ICT and Business studies. The most preferred programmes were; 
1. ICT (Web Design), 2. Accounting, 3. Religious Studies, 4. Economics, 5. Finance

One of those who opted for Web Design argued as follows:

I have the desire to be a web designer so that I can help young businesses to have website addresses and therefore advertise themselves. With this knowledge, I can contribute to business development in Ghana (P10)

One key reason for wanting to study religious studies was articulated by a participant as follows:

As a result of being in this situation, I mean in incarceration, I have developed an intimate relationship with my maker so I want to study His word into details so that I can confidently 07share it wherever I find myself. Both here and out of here (P 7)

For those who have the desire to the major reason was that they want to manage their own businesses after release. The following quotations capture this line of thinking.

Through accounting and economics, I hope to acquire the business sense to run my little enterprise... to manage it well (P6)

I need a sound background in business and commerce especially finance to handle any business I will do very well. Eeeeerrr ......most businesses collapse because most of those who start them don't have any business or accounting background. (P14)

With knowledge of economics and commerce, I hope to make my own leaving and succeed as a in business. I don't want to work for anybody to put me into trouble again. ( $\mathrm{P} 3$ )

Thus there is a strong desire among the inmates to run their own private businesses upon release, which a laudable idea because it will help grow the private sector.

\section{Facilities Required For Distance Education Learning}

In terms of the facilities needed to be put in place by the Prison authorities or Government to ensure smooth distance education, one participant said:

I will need software of the programme to enhance my study. Additionally, a well-equipped library for studies and adequate training for the facilitators will be needed (P 8).

Another ICT student inmate opined that:

I need access to the internet and well-equipped library. Sponsorship to study up to master's degree level and School feeding programme will be required (15)

All the participants felt they will need financial support as well as personal ICT devices like laptops, tablets and smart phones if they are to study through ODL 
successfully. The financial support will enable them to meet the cost associated with the studies. For example, an inmate commented:

......I know distance education involves a lot of cost, paying for cost materials, buying leaning devices like mini computers, smart phones and data.... hmm. Money matter (P 4)

Another added:

To be able to study successfully through ODL financial and logistical support should be available... hahahahaah, even we need more food because studies goes with good feeding, hahahaha (13).

\section{DISCUSSION}

The study has shown that prior to imprisonment, majority of participants had fair knowledge of distance education. Participants shared the view that, distance education can effectively reach those learners who have been denied access to education as a result of circumstances. For example, people who dropped out of school or were imprisoned whilst they were pursuing educational programmes in school the second chance to do so. This finding corroborates with that of Chukwunka (2017) which found a strong believe in using ODL for reformation by prisoners in Nigeria. Again, the expressions of participants regarding the benefits of the open and distance learning in this study confirms that, Open Distance Learning (ODL) can effectively reach those learners who have been denied access to education. For example, people who are unable to attend traditional programmes because of family constraints (like death of parents), poverty, unemployment and imprisoned (Rumble, 2000).

Secondly, majority of the participants were aware that the public universities such as University of Ghana, Legon, University of Cape Coast, University of Education, Winneba and Kwame Nkrumah University of Science and Technology as well as private universities like Wisconsin University and Regional Maritime University College offer distance education to Ghanaian workers and school leavers.

Some of them expressed the desire to pursue ICT (Web Design), Accounting, Religious Studies, Economics and Finance when the distance education programme is offered in prison. The study found that the main justification for opting for the above programmes is that the inmates want to be on their own after release. While on the surface, it connotes the idea of entrepreneurship, it can arguably be also due to the criminal of Law of Ghana which forbids ex-convicts from being employed in the public sector.

For participants to pursue programmes of their choice when distance education is offered in prison, participants requested for monthly stipend and scholarship to enable them secure textbooks, laptops and other devices. As a way of motivation, participants also requested for delicious meals, clothing, and better accommodation, well-equipped library for studies and adequate training for their tutors who qualify as facilitators or lecturers. This would ensure that, effective teaching and learning could take place when the greater part of educational materials were provided on time. 
The finding resonates the scholarly work of Zimkle, (2001). Zimkle (2001) identified specific challenges facing distance learners as programme costs, lack of equipment and infrastructure, instructional concerns and poor technical assistance. The challenge associated with programme cost might account for the free scholarship scheme operated by NOUN (NOUN, 2018).

\section{CONCLUSION}

The study has demonstrated that prisoners in NMSP have knowledge and understanding about the potential benefits of ODL in equipping them with knowledge and skills needed for after prison life. They have also expressed the desire to study through ODL but indicated that they will need financial and logistical support. One interesting finding is their desire for start their own businesses with knowledge and skills to be acquired. These findings have some implication for Prison educational policy for the Government. It points the need for the government to provide financial support and logistical support for effective correctional educational through ODL. Future providers of ODL programmes for inmates should emphasise entrepreneurial studies to prepare inmates to be successful growers of the private sector.

\section{References}

Acheampong, S. (2007). Male/female criminality-comparative predisposing factors: A case study at medium security prison. Unpublished project work, University of Ghana, Legon.

Adelaja, A. (2009). State of Nigeria prisons. Retrieved on November 3, 2009, fromhttp://234next.com/csp/cms/sites/Next/Home/5250407-

Ahwa-Yankey, M. (2014, July 29). An address delivered at Police Training Depot at Pwalugu. The Ghanaian Times, $p .9$.

Ampratwum, .J.K (2002). A useful guide book for Prison Officers. Accra: Skyco Printing Press Ltd

Antwi, A. (2015). Social reintegration of offenders and recidivism in Ghana. Unpublished Doctoral Thesis, University of Ghana, Legon.

Attafuah, A. K. (2008). Fighting armed robbery in Ghana. Accra. The Justice \& Human Rights Institute.

Chukwunka, C.A.C., (2017). National Open University of Nigeria and Reformation of Prison Inmates through Open and Distance Learning, West African Journal of Open \& Flexible Learning Volume 5, Number 2

Check, J., \& Schutt, R. K. (2012). Research methods in education. London: Sage Publication.

Daniel, J. (2005). Preface. In Perspectives on Distance Education: Lifelong learning \& Distance Higher Education (C. McIntosh \& Z. Varoglu eds.). Vancouver/France: $\mathrm{UNESCO} / \mathrm{COL}$

Denscombe, M. (2010). The good research guides (4th ed.). New York: Open University Press.

Hagan, K. (2013). The impact of rehabilitation programmes on inmates at Nsawam Prisons. Unpublished Master of Philosophy dissertation, University of Ghana, Legon.

Holmberg, B. (1990). Status and trends of distance education. London: Kogan Page. 
Kyale, S., \& Brinkman, S. (2009). Interviews: Learning the craft of qualitative research interviewing (2nd ed.). Thousands Oaks, CA: Sage

Marshalll, C., \& Rossman, G. B. (2010). Designing qualitative research (5th ed.). Thousand Oaks, CA: Sage Publication.

Mfum, C. (2012). Prospects and challenges of prison libraries in Ghana: A case study of Nsawam Medium Security Prison. Winneba: University of Education, Winneba.

NOUN (2018). More prisoners embrace NOUN's Free Scholarship. A Monthly Bulletin of the National Open University of Nigeria, Vol. 27, No. 7.

Notshulwana, V. (2012). Rehabilitation of youth offenders in South Africa: The relevance of ecological model and graduated sanctions. Africa Insight, 41(4), 139-158.

Petersilia, J. (2003). When prisoners come home: parole and prisoner reentry. New York: Oxford University Press.

Rumble, G. (200) The management of distance learning systems, Paris UNESCO/International Institute for Educational Planning.

Saint, W. (1999). Tertiary distance education and technology in Sub-Sahara Africa. Washington DC: The World Bank.

Ugwuo, K.A. (2015). An Aetiological Study of Criminal Recidivism In Nigeria. Journal for Studies in Management and Planning, Vol.01, No. 11.

UNESCO (2004). Final report of the meeting of higher education papers, World Conference on Higher Education. Paris: UNESCO.

Zimkle, C. (2004). Utilization of distance education in two-year colleges: Implications for technical education. Minneapolis: America Technical Education Association 